\title{
Association of Breast Cancer Risk, Density, and Stiffness: Global Tissue Stiffness on Breast MR Elastography (MRE)
}

Bhavika Patel ( $\sim$ patel.bhavika@mayo.edu )

Mayo Clinic Arizona https://orcid.org/0000-0002-8486-955X

Kay Pepin

Mayo Clinic Rochester: Mayo Clinic Minnesota

Kathy Brandt

Mayo Clinic Rochester: Mayo Clinic Minnesota

Gina Mazza

Mayo Clinic Arizona

Barbara Pockaj

Mayo Clinic Arizona

Jun Chen

Mayo Clinic Rochester

Yuxiang Zhou

Mayo Clinic Arizona

Donald Northfelt

Mayo Clinic Arizona

Karen Anderson

Mayo Clinic Arizona

Juliana Kling

Mayo Clinic Arizona

Kristin Swanson

Mayo Clinic Arizona

Mehdi Nikkhah

Arizona State University

Richard Ehman

Mayo Clinic: Mayo Clinic Minnesota

\section{Research Article}

Keywords: breast cancer risk, dense breasts, breast tissue stiffness, breast MR imaging, breast elastography, breast stroma 
Posted Date: June 15th, 2021

DOl: https://doi.org/10.21203/rs.3.rs-611943/v1

License: (c) (i) This work is licensed under a Creative Commons Attribution 4.0 International License. Read Full License 


\section{Abstract}

Purpose:

Quantify in vivo biomechanical tissue properties in various breast densities and in normal risk and high risk women using Magnetic Resonance Imaging (MRI)/MRE and examine the association between breast biomechanical properties and cancer risk.

Methods: Patients with normal risk or high risk of breast cancer underent 3.0 T breast MR imaging and elastography. Breast parenchymal enhancement (BPE), density (from most recent mammogram), stiffness, elasticity, and viscosity were recorded. Within each breast density group (non-dense versus dense), stiffness, elasticity, and viscosity were compared across risk groups (normal versus high). A multivariable logistic regression model was used to evaluate whether the MRE parameters (separately for stiffness, elasticity, and viscosity) predicted risk status after controlling for clinical factors.

Results: 50 normal risk and 86 high risk patients were included. Risk groups were similar on age, density, and menopausal status. Among patients with dense breasts, mean stiffness, elasticity, and viscosity were significantly higher in high risk patients $(N=55)$ compared to normal risk patients $(N=34$; all $p<0.001)$. Stiffness remained a significant predictor of risk status (OR=4.26, 95\% $\mathrm{Cl}[1.96,9.25])$ even after controlling for breast density, BPE, age, and menopausal status. Similar results were seen for elasticity and viscosity.

Conclusion: A structurally-based, quantitative biomarker of tissue stiffness obtained from MRE is associated with differences in breast cancer risk in dense breasts. Tissue stiffness could provide a novel prognostic marker to help identify high risk women with dense breasts who would benefit from increased surveillance and/or risk reduction measures.

\section{Background}

Fifty percent of screening-eligible women have high mammographic breast density (MBD). MBD is a strong risk factor for breast cancer, with a 4 to 6 fold increased risk in women with dense tissue compared to those with minimal dense tissue ${ }^{1}$. As such, increased areas of breast density may be more susceptible to the initation and promotion of breast cancers. However, breast cancer risk is not uniformly elevated across women with dense breasts ${ }^{2}$.

Because half of all women have dense breat tissue, there is significant interest in developing imaging biomarkers to improve personalized risk stratification and identify which women with dense breasts are, in fact, at elevated risk for breast cancer. Doing so will enable appropriate imaging surveillance, reduce unnecessary additional screening, and enable effective risk-reducing strategies for women with dense breasts. 
Studies have shown that the variation in the risk associated with breast density may be related to differences in the breast microenvironment at a microscopic level ${ }^{3-6}$. More recently, studies using quantitative proteomics, collagen analyses, and mechanical measurements have demonstrated that mammographichally-dense tissues have increased collagen density, breast stroma stiffness, and higher epithelial cell density ${ }^{7-9}$. These mechanical properties of tissue play a major role in the development and progression of disease states and have been studied in multiple parts of the body ${ }^{10-12}$. Preliminary studies, performed in vitro, in animal models, or in small numbers of patients (livers and other organs), show this hypothesis to be true and also valid in relation to breast cancer development. An in vivo study in mice ${ }^{13}$ demonstrated a causal link between increased stroma collagen deposition and enhanced tumorigenesis, local invasion, and metastases. These interactions may in turn affect oncogenesis and contribute to increased cancer risk in dense breasted women ${ }^{4,14,15}$.

With the advent of MR elastography, quantitative biomechanical properties, such as tissue stiffness, elasticity and viscosity, have become viable imaging biomarkers to better understand the tissue microenvironment. MRE is a promising, noninvasive imaging technology capable of quantifying tissue mechanical properties ${ }^{16-19}$ in vivo in patients. It assesses the viscoelastic shear properties of lesions through direct MR visualization of acoustic waves and demonstrates decreased elasticity in malignant tumors. As such, MRE allows an objective, quantitative analysis of the viscoelastic properties of normal and diseased breast tissues, providing greater insight into the study of and treatment of breast cancer. We hypothesize that the distinctive biomechanical properties of microenvironments can be assessed by MRE, and may account for the varying risk patterns for breast cancer in patients with similar densities. In this study, we will quantify in vivo biomechanical tissue properties, such as breast stiffness, elasticity and viscosity, in various breast densities in both normal and high risk women using Magnetic Resonance Imaging (MRI)/MRE. We will also examine the association of biomechanical properties of the breast with cancer risk.

\section{Materials And Methods}

\section{Patients}

In this institutional review board-approved prospective single-institution study, we recruited two groups of women with different breast cancer risk to undergo a 3.0 T dynamic contrast enhanced MRI/MRE of the breast. Normal risk women were defined as having no personal history of breast cancer, no prior high risk breast biopsies, no self-reported significant family history of breast cancer, and a negative mammogram within 12 months (Table 1). Normal risk patients were at least 35 years old, not pregnant, not breastfeeding, had no imaging abnormality on mammography or sonography (Breast Imaging Reporting and Data System [BI-RADS] 1 or 2), and had no contraindications to MRI or contrast agents.

High-risk breast cancer patients were recruited from patients who received standard of care breast MR for routine evaluation (patients with prior breast cancer history or those who were deemed at lifetime risk of 
$20 \%$ or greater based on Tryir Czuick scores ${ }^{20-23}$ ). All prospectively collected patients provided informed written consent. High-risk patients were at least 26 years of age, not pregnant, not breastfeeding, had no imaging abnormality on mammography or sonography (Breast Imaging Reporting and Data System [BIRADS] 1 or 2), and had no contraindications to MRI or contrast agents.

Exclusion criteria were incomplete examinations and technical failures.

\section{Imaging}

All patients received combined 3-T multiparametric contrast-enhanced breast MRI and breast elastography.

\section{Breast MRE}

Magnetic resonance elastography (MRE) is a safe and novel non-invasive imaging technique to quantitatively assess the mechanical properties of soft tissues using MR imaging. The key component of elasticity imaging is to characterize the tissue response of the stress. In general, MRE imaging consists of the following steps: 1) Deliver shear waves in the tissues to be imaged; 2) Measure tissue displacement; 3) Generate quantitative stiffness maps (elastograms).

Our breast MRE exam is naturally integrated into the established breast CEMRI / MRI clinical protocol, avoiding the need to switch RF coils or reposition patients. Our current breast MRE protocol is previously published ${ }^{24}$ and the breast MRE sequence is added at the conclusion of the clinical portion of the exam.

The breast MRE protocol is performed using a gradient echo phase contrast sequence ${ }^{25}$. A pillow-like passive driver is positioned between the breasts under the sternum while the patient lies prone in a standard breast coil ${ }^{24}$. Low frequency vibrations of $40 \mathrm{~Hz}$ are transmitted to the passive driver from an active driver (Resoundant, Inc., Rochester, $\mathrm{MN}$ ) located outside the scan room during the entire duration of image acquisition (5-7 minutes). Breast MRE data is obtained from 40 axial slices, centered at the breast along the superior-inferior direction. A modified 3D-GREMRE pulse sequence is used with the following major parameters [9]: vibration frequency $=40 \mathrm{~Hz} ; \mathrm{FOVx} / \mathrm{y} / \mathrm{z}=38.4 / 38.4 / 12 \mathrm{~cm}$; flip angle $=8^{\circ} ; \mathrm{TR}=22.2-$ $22.9 \mathrm{~ms}, \mathrm{TE}=15.9-18.1 \mathrm{~ms}$ (fat/water in-phase); axial bilateral imaging plane; matrix = $96 \times 96 \times 30 ; 8$ motion cycles per 9 TRs ( 3 phase offsets); motion sensitivity $(M E N C)=12.3$ micron/radian; motion encoding directions $=x / y / z$; scan time $=5^{\prime} 25^{\prime \prime}-5^{\prime} 42^{\prime \prime}$ (free breathing). 3D wave images are processed with 3D multiple-model direct inversions without directional filtering, generating 3D elastograms of bilateral breasts.

\section{Breast MRE measurements}

Regions of interest are then drawn over the central slice (at the level of the nipple) and custom, in-house software is used to obtain MRE stiffness values. Quantitative breast stiffness and viscosity measurements were obtained as described previously ${ }^{24}$ by drawing whole breast region of interest (ROI) around the breast tissue (at the center slice). This was drawn on the magnitude images which 
demonstrate anatomy the best.. The wave images were analyzed to assess the adequacy of wave penetration through breast tissue. The ROI was then copied and translated onto the stiffness and viscosity maps to obtain the global breast MRE measurement.

\section{Multiparametric breast MRI}

A dynamic contrast enhanced image set was also acquired with the first series being an unenhanced fatsaturated gradient-recalled echo T1-weighted sequence (VIBRANT) followed by three dynamic contrastenhanced fat-saturated T1-weighted gradient-recalled echo series (VIBRANT) performed after IV administration of Gadobutrol (Gadavist, Bayer) at $30 \mathrm{sec}, 3 \mathrm{~min}$ and 6 min with the use of a T1-weightbased dosing protocol. The dynamic contrast images were acquired in the sagittal orientation (TR/TE = $5.1 / 2.4 \mathrm{~ms}$; matrix = $256 \times 256$ ). Automatic post-processing included the generation of subtraction images between pre and post contrast images produced after each phase. Late gadolinium fatsuppressed T1- weighted fast-spoiled-gradient-echo (FSPGR) sequences were also acquired for both right and left side separately in the axial orientation (TR/TE $=115 / 3.15 \mathrm{~ms}$; matrix $=256 \times 192, \mathrm{NEX}=2$ ). T2 weighted sagittal and T1 weighted FSE AX images were obtained pre-contrast.

\section{Statistical Analysis}

In both the normal risk and high risk groups, the following breast imaging features were recorded: breast parenchymal enhancement (BPE); breast density (from most recent MG); tissue stiffness, elasticity, and viscosity. Patient demographic and disease characteristics were summarized for the full sample and by risk status; comparisons were conducted across risk groups (normal versus high) using two-sample $t$ tests (for continuous variables) or Fisher's exact test (for categorical variables). Breast stiffness, elasticity, and viscosity were averaged across the left and right breasts. If breast stiffness, elasticity, or viscosity was missing for one breast, then the value observed for the contralateral breast was used. For the full sample and within each breast density group (non-dense versus dense), two-sample t-tests allowing for unequal variances were conducted to compare breast stiffness, elasticity, and viscosity across risk groups (normal versus high). Separately for breast stiffness, elasticity, and viscosity, a multivariable logistic regression model was used to evaluate whether the MRE parameter predicted risk status after controlling for clinical factors. A nominal significance level of $a=0.05$ was used for all analyses.

\section{Results}

\section{Patients}

From February 2017 to November 2019, there were 57 normal risk and 86 high risk patients recruited to the study. Of the 57 low-average risk patients, 50 who met the inclusion criteria were included in the normal risk portion of the study (mean age $=55.6$ years, range $=39.0-74.0$; Table 1 ); 2 were excluded for incomplete examinations and 5 were excluded for technical failures. Eighty-six patients who fulfilled the 
inclusion criteria were included in the high risk portion of the study (mean age $=53.6$ years, range $=26.0-$ 76.0; Table 1).

As shown in Table 1, normal risk and high risk women did not significantly differ in their mean age (mean age $=55.6$ vs. 53.6 years, $p=0.27)$, density $(68.0 \%$ vs. $64.0 \%$ dense breasts, $p=0.71)$, or menopausal status $(66.0 \%$ vs. $69.8 \%$ were post-menopausal, $p=0.70)$.

Table 1

Patient Demographic Characteristics by Risk Status

\begin{tabular}{|c|c|c|c|c|}
\hline Characteristic & $\begin{array}{l}\text { Normal Risk } \\
(N=50)\end{array}$ & $\begin{array}{l}\text { High Risk } \\
(N=86)\end{array}$ & $\begin{array}{l}\text { Total } \\
(N=136)\end{array}$ & $p$ Value $^{1}$ \\
\hline Age in Years (Mean, $S D$ ) & $55.6(10.2)$ & $53.6(11.3)$ & $54.3(10.9)$ & 0.27 \\
\hline Breast Density (\#, \% Dense) & $34(68.0 \%)$ & $55(64.0 \%)$ & $89(65.4 \%)$ & 0.71 \\
\hline Prior Breast Cancer (\#, \% Yes) & $0(0.0 \%)$ & $28(32.6 \%)$ & $28(20.6 \%)$ & - \\
\hline Biopsy-Proven High Risk Lesion (\#, \% Yes) & $0(0.0 \%)$ & $12(14.0 \%)$ & $12(8.8 \%)$ & - \\
\hline Biopsy or Surgery in Either Breast (\#, \% Yes) & $7(14.0 \%)$ & $50(58.1 \%)$ & $57(41.9 \%)$ & $<0.001$ \\
\hline Menopausal Status (\#, \% Post-Menopausal) & $33(66.0 \%)$ & $60(69.8 \%)$ & $93(68.4 \%)$ & 0.70 \\
\hline On Hormone Replacement Therapy (\#, \% Yes) & $5(10.0 \%)$ & $8(9.3 \%)$ & $13(9.6 \%)$ & $>0.999$ \\
\hline $\begin{array}{l}\text { 1st Degree Relative with Breast Cancer (\#, \% } \\
\text { Yes) }\end{array}$ & $0(0.0 \%)$ & $64(74.4 \%)$ & $64(47.1 \%)$ & - \\
\hline \multicolumn{5}{|c|}{$\begin{array}{l}{ }^{1} \text { For age in years, the } p \text {-value was based on a two-sample } t \text {-test allowing for unequal variances. For all } \\
\text { other patient demographic and disease characteristics, the } p \text {-value was based on Fisher's exact test. } \\
\text { Em dashes indicate that the } p \text {-value was not calculated because high risk status was defined by prior } \\
\text { breast cancer, biopsy-proven high risk lesion, and family history of breast cancer. }\end{array}$} \\
\hline
\end{tabular}

\section{Breast MRI BPE measurements}

Breast background parenchymal enhancement was routinely assessed on a BIRADS scale ${ }^{26}$ (minimal, mild, moderate, marked) by standard of care within the imaging reports by one of five breast fellowship trained radiologists. Background parenchymal enhancement was stratified into 2 cohorts on MRI (mininal or mild versus moderate or marked) and did not significantly differ between the normal risk and high risk cohorts, $p=0.56$.

\section{Breast MRE measurements}

Quantitative breast stiffness and viscosity measurements were significantly higher in the high-risk dense breast cohort compared to that of the normal risk dense breast cohort (Figs. 1, 2). The means were not significantly different between those with dense versus non-dense breasts in the normal risk patient cohort ( $p=0.14$ for breast stiffness, $p=0.78$ for breast viscosity; Table 2). Similarly, the means were not significantly different between those with dense versus non-dense breasts in the high risk patient cohort 
( $p=0.09$ for breast stiffness, $p=0.13$ for breast viscosity; Table 2, Fig. 3). In those women who had a prior breast surgery or biopsy, mean breast stiffness did not significantly differ between the surgerized or biopsied breast versus contralateral breast (Table 3, Figs. 4 and 5).

Among patients with dense breasts, mean stiffness, elasticity, and viscosity were significantly higher in high risk patients $(N=55)$ compared to normal risk patients $(N=34$; all $p<0.001)$.

In the multivariable logistic regression model, breast stiffness remained a significant predictor of risk status ( $\mathrm{OR}=4.26,95 \% \mathrm{Cl}[1.96,9.25])$ even after controlling for breast density, MRI BPE, age, and menopausal status. Similar results were seen for breast elasticity $(\mathrm{OR}=4.88,95 \% \mathrm{Cl}[2.08,11.43])$ and viscosity $(\mathrm{OR}=11.49,95 \% \mathrm{Cl}[1.15,114.89])$. 
Table 2

Magnetic Resonance Elastography (MRE) Parameters and Magnetic Resonance Imaging (MRI) Background Parenchymal Enhancement (BPE) by Risk Status and Breast Density

\begin{tabular}{|c|c|c|c|c|c|c|}
\hline \multirow[t]{2}{*}{ Characteristic } & \multicolumn{3}{|l|}{ Normal Risk } & \multicolumn{3}{|c|}{ High Risk } \\
\hline & $\begin{array}{l}\text { Non-Dense } \\
(N=16)\end{array}$ & $\begin{array}{l}\text { Dense } \\
(N=34)\end{array}$ & pValue ${ }^{1}$ & $\begin{array}{l}\text { Non- } \\
\text { Dense } \\
(N=31)\end{array}$ & $\begin{array}{l}\text { Dense } \\
(N=55)\end{array}$ & pValue $^{1}$ \\
\hline \multicolumn{3}{|l|}{ Breast Stiffness } & \multirow[t]{3}{*}{0.14} & & & \multirow[t]{3}{*}{0.09} \\
\hline Mean $(S D)$ & $1.07(0.18)$ & $\begin{array}{l}1.16 \\
(0.21)\end{array}$ & & $\begin{array}{l}1.69 \\
(1.19)\end{array}$ & $\begin{array}{l}2.14 \\
(1.12)\end{array}$ & \\
\hline Median (Range) & $\begin{array}{l}1.05(0.65- \\
1.44)\end{array}$ & $\begin{array}{l}1.15 \\
(0.76- \\
1.67)\end{array}$ & & $\begin{array}{l}1.09 \\
(0.54- \\
4.36)\end{array}$ & $\begin{array}{l}1.37 \\
(0.92- \\
4.09)\end{array}$ & \\
\hline \multicolumn{3}{|l|}{ Breast Elasticity } & \multirow[t]{3}{*}{0.01} & & & \multirow[t]{3}{*}{0.06} \\
\hline Mean $(S D)$ & $0.96(0.15)$ & $\begin{array}{l}1.10 \\
(0.20)\end{array}$ & & $\begin{array}{l}1.57 \\
(1.08)\end{array}$ & $\begin{array}{l}2.03 \\
(1.08)\end{array}$ & \\
\hline Median (Range) & $\begin{array}{l}0.96(0.61- \\
1.21)\end{array}$ & $\begin{array}{l}1.10 \\
(0.74- \\
1.58)\end{array}$ & & $\begin{array}{l}1.03 \\
(0.52- \\
3.85)\end{array}$ & $\begin{array}{l}1.32 \\
(0.74- \\
3.99)\end{array}$ & \\
\hline \multicolumn{3}{|l|}{ Breast Viscosity } & \multirow[t]{3}{*}{0.78} & & & \multirow[t]{3}{*}{0.13} \\
\hline Mean $(S D)$ & $0.23(0.09)$ & $\begin{array}{l}0.23 \\
(0.07)\end{array}$ & & $\begin{array}{l}0.26 \\
(0.27)\end{array}$ & $\begin{array}{l}0.35 \\
(0.24)\end{array}$ & \\
\hline Median (Range) & $\begin{array}{l}0.23(0.08- \\
0.39)\end{array}$ & $\begin{array}{l}0.23 \\
(0.11- \\
0.44)\end{array}$ & & $\begin{array}{l}0.20 \\
(0.0- \\
1.39)\end{array}$ & $\begin{array}{l}0.27 \\
(-0.05- \\
1.05)\end{array}$ & \\
\hline BPE (\#, \% Minimal or Mild) & $14(87.5 \%)$ & $20(58.8 \%)$ & 0.06 & $\begin{array}{l}28 \\
(90.3 \%)\end{array}$ & $\begin{array}{l}35 \\
(63.6 \%)\end{array}$ & 0.01 \\
\hline \multicolumn{7}{|c|}{$\begin{array}{l}\text { Breast stiffness, elasticity, and viscosity were averaged across the left and right breasts. } \\
{ }^{1} \text { For breast stiffness, elasticity, and viscosity, the } p \text {-value was based on a two-sample } t \text {-test allowing } \\
\text { for unequal variances. For BPE, the } p \text {-value was based on Fisher's exact test. }\end{array}$} \\
\hline
\end{tabular}


Table 3

Breast Stiffness in Patients with 1 Surgerized Breast and 1 Unaffected Breast

\begin{tabular}{|c|c|c|c|c|}
\hline \multirow[t]{2}{*}{ Patient Group } & \multirow[t]{2}{*}{$N$} & \multicolumn{2}{|c|}{ Breast Stiffness Mean (SD) } & \multirow[t]{2}{*}{$p$ Value $^{1}$} \\
\hline & & Unaffected Breast & Surgerized Breast & \\
\hline Normal Risk & 7 & $1.07(0.12)$ & $1.07(0.15)$ & - \\
\hline High Risk & 33 & $2.33(1.23)$ & $2.22(1.17)$ & - \\
\hline Total & 40 & $2.11(1.21)$ & $2.02(1.15)$ & 0.14 \\
\hline
\end{tabular}

\section{Discussion}

The most striking results in our prospective study to understand global breast stiffness in normal and high risk patients, is the significantly higher stiffness of breast tissue in the high-risk (prior breast cancer history or high risk based on lifetime risk of greater than $20 \%$ ) dense breasted patients compared to the normal risk dense breasted patients. Patients that had prior unilateral post-operative and/or posttreatment related radtaion change did not show a significant difference in MRE parameters between the treated and untreated breast. Our study suggests that the structurally-based (tissue stiffness) risk information obtained from MRE could be used to identify the subset of women with dense breasts most likely to benefit from increased surveillance and serve as a prognostic biomarker in screening breast cancer patients. These differences in stiffness were also seen between high risk and normal risk patients with non-dense breasts, although is less clinically significant as the performance of screening mammography is better in non-dense breasts.

Through translational studies ${ }^{27,28}$, one biologic explanation for the increased risk of breast cancer in dense breasted patients suggests that increased collagen deposition, tissue tensile strength and collagen structural differences may contribute to increased mammographic density which then is associated with breast cancer initiation $4,14,15,29-36$. In fact, increasing evidence indicates that the tumor microenvironment plays a critical role in regulating the biologic behavior of, and predisposition to breast cancer ${ }^{37,38}$. Recent studies have shown that organization and stiffness of the collagen matrix are important in mediating tumor growth and invasion ${ }^{3,4,28,39-41}$. Abnormal changes in the amount and organization of extracellular matrix lead to altered biochemical, physical, and biomechanical properties of tumor-associated ECM that contribute to tumor progression ${ }^{42,43}$.

In a similar light, a 2002 study investigated the feasibility of MRE to distinguish malignant and benign properties of breast tissue. Analysis of MR elastograms using a $65 \mathrm{~Hz}$ frequency on 20 female patients with malignant and benign breast lesions and 15 healthy volunteers as the control demonstrated that 
cancerous growths consistently demonstrated higher elasticity values (greater stiffness) in contrast to surrounding tissue. Malignant breast tumors measured a median stiffness of $15.9 \mathrm{kPa}$ while adjacent breast parenchyma and fatty tissue measured a median of only $2.5 \mathrm{kPa}$ and $2.0 \mathrm{kPa}$, respectively. Furthermore, the difference in stiffness between malignant and benign tumors were also evident through MRE where benign breast lesions were determined to be at a median value of $7.0 \mathrm{kPa}$. In fact, quantitatively, the stiffness value of breast carcinomas was, on average, $418 \%$ higher than the value of the adjacent tissues, $(p<0.05)^{44}$. The differing values of malignant tumors, benign tumors, and surrounding breast tissue illustrates that MRE as an imaging technique is able to accurately differentiate these tissues, and therefore of clinical importance ${ }^{44-46}$.

Clinically, we know that over $40 \%$ of our breast cancer screening patients have dense breasts ${ }^{47}$. As a result of relatively new dense breasts notification laws, these patients are now being told that they have dense breast tissue (which could result in decreased sensitivity of mammography screening and increase their risk of breast cancer). Providers are encouraged to discuss these details with patients and where appropriate, offer various forms of supplemental dense breast screening ${ }^{48-50}$. These supplemental screening examinations can find additional cancers, however, also result in increased false positive results ${ }^{23,51,52}$. Since the risks and benefits of screening test are functions of each patient's density features and risk factors, personal screening policies tailored to individuals are necessary and the new paradigm of breast cancer screening. Personalized breast cancer screening algorithms will result in cost efficiencies ${ }^{53-58}$ and reduced false positive rates. As such, our data is promising whereby imaging biomarker of global breast tissue stiffness could provide an additional component in a clinical decision making tool to guide providers of screening and risk-reduction measures based on patient values and preferences.

In our study we observed a nonsignificant increase in stiffness in both the dense and non-dense breasts. These observed differences with increasing stiffness with density are consistent with other smaller studies $^{59-61}$, however the lack of a statistical significance is unique in our study. It should be noted that our study had few cases included along the the extreme spectrum of breast densities, fatty $(n=1)$ and extremely dense $(n=3)$ in our normal risk cohort, which may be affecting our results of statistical significance. Also it should be noted in our study, we chose to use the central slice as a first step to assess global 3D MRE values and used a $40 \mathrm{~Hz}$ frequency on a 3T scanner. The region of interest included the central breast tissues, including fatty tissue and breast parenchyma on the slice, sparing the edges. This technique is similar to the annotations drawn and lessons learned on clinical diagnostic liver MRE. Contrast this technique to that of a 2017 study that demonstrated that dense breasts had significantly higher stiffness measurements compared with non-dense breasts $\left(p<0.05^{61}\right)$ the authors used a $60 \mathrm{~Hz}$ frequency on the $3 \mathrm{~T}$ scanner which requires less power for penetration. We speculate that the stiffness is highly dependent on the measurement method and the tissues that are covered.

Limitations within our study highlight the need for further inquiry to fill the gaps of current research before implementation in clinical practice. Our study is one of the largest to date, other published breast 
MRE studies have been performed using a small sample cohort of approximately 20 to 50 patients, limiting the representation of breast tissue density. In addition, the high risk volunteers used for testing the efficacy of MRE had a included those with a personal history breast cancer, making it difficult to extrapolate the results to the general screening population. Thus, future research should aim to encompass a larger set of patients to account for individual differences in breast tissue and a variety of lesion characteristics. Given the current study is based on self- reported family history, we will also plan to calculate lifetime and 5 year risks for patients based on acccepted clinical breast cancer risk models ${ }^{62-}$ 64 . Doing so, will allow us to have more accurate correlations to lifetime risk rather than the current stratification provided here. Another limitation is the fairly homogenous demographics of the patient population in this study. Therefore adding demographic variation to the population will be of utmost interest given the variations seen in breast density based on racial differences ${ }^{65-67}$. Also, future studies should include computer-generated volumetric breast density from MG to classify pateints as dense or non dense, given the considerable inter- and intra-reader variability within the mammographic density reporting system ${ }^{68,69}$.

As more personalized approach within the breast cancer screening regimen develops, further risk stratification using quantitative imaging biomarker of global breast stiffness could inform more effective personalized screening regimens.We anticipate the results of this study and ours will give light to more investigations on how tissue stiffness correlates with breast cancer risk and prognosis. These prior studies and our results provide support for the further study of MRE given its ability to assess the viscoelastic properties of breast tumors and the surrounding tissue ${ }^{70-72}$. While the studies on MRE's application to in vivo breast tissue are limited, this trial substantiates the capabilities of MRE and its potential for a risk stratification tool in women with dense breasts.

\section{Conclusions}

In conclusion, our work above suggests structurally-based, quantitative biomarker of tissue stiffness obtained from global 3D breast MRE could provide a novel prognostic marker used to identify the subset of high-risk women with dense breasts. As such, a stiffness values could help stratify dense breasted pateints into those who are at elevated risk and would benefit from increased surveillance with supplemental imaging techniques and/or risk reduction measures.

\section{Declarations}

Acknowledgments: We would like to think the Mayo Clinic Cancer Center for providing grant funding for this study. We would also like to acknowledge the Women's Health staff who have been instrumental with recruitment for this study and the breast imaging staff who helped with imaging patients using this new technology. Special thanks to Diana Almader-Smith who assisted with formatting the references for this manuscript.

Funding: This study was funded by the Mayo Clinic Cancer Center MEGA grant. 
Conflict of Interest: BKP has received unrelated grant funding from GRAIL Inc. and Hologic Inc. with monies directed to Mayo Clinic. Dr. Kay Pepin is an employee at Resoundant Inc. Dr. Jun Chen is an employee, holds patents and intellectual property at Resoundant Inc. Dr. Yuxiang Zhou holds intellectual property in interventional MRI. Dr. Northfelt has research funding with Genentech/Roche (Inst); GlaxoSmithKline (Inst); Incyte (Inst); Merck (Inst); Novartis (Inst); Pfizer (Inst), Dr. Anderson has Stock and Other Ownership Interests - FlexBioTech; SafeGen Therapeutics, Consulting or Advisory Role and research funding from Merck, Dr. Vachon I don't have insurance owns stock inexact sciences, receives research funding from grail, has intellectual property with breast density software algorithms and has received travel expenses from GRAIL Inc. Dr Ehman owns stock, has research funding, and discloses uncompensated relationships with Resoundant. Dr. Swanson discloses Precision Oncology Insights Inc. Drs. Ehman and Mayo Clinic have financial interest and intellectual properties related to MR Elastography.

\section{References}

1. Boyd NF, Lockwood GA, Byng JW, Tritchler DL, Yaffe MJ (1998) Mammographic densities and breast cancer risk. Cancer Epidemiology Prevention Biomarkers 7(12):1133-1144

2. Vachon $\mathrm{CM}$, Brandt KR, Ghosh $\mathrm{K}$ et al (2007) Mammographic breast density as a general marker of breast cancer risk. Cancer Epidemiology Prevention Biomarkers 16(1):43-49

3. Acerbi I, Cassereau L, Dean I et al (2015) Human breast cancer invasion and aggression correlates with ECM stiffening and immune cell infiltration. Integr Biol (Camb) 7(10):1120-1134

4. Levental KR, Yu H, Kass L et al (2009) Matrix crosslinking forces tumor progression by enhancing integrin signaling. Cell 139(5):891-906

5. McConnell JC, O'Connell OV, Brennan K et al (2016) Increased peri-ductal collagen microorganization may contribute to raised mammographic density. Breast Cancer Res 18(1):5

6. Mouw JK, Ou G, Weaver VM (2014) Extracellular matrix assembly: a multiscale deconstruction. Nat Rev Mol Cell Biol 15(12):771-785

7. Ghosh K, Brandt KR, Reynolds C et al (2012) Tissue composition of mammographically dense and non-dense breast tissue. Breast cancer research treatment 131(1):267-275

8. Martin LJ, Boyd NF (2008) Mammographic density. Potential mechanisms of breast cancer risk associated with mammographic density: hypotheses based on epidemiological evidence. Breast Cancer Research 10(1):1-14

9. Martin LJ, Boyd N (2008) Potential mechanisms of breast cancer risk associated with mammographic density: hypotheses based on epidemiological evidence. Breast Cancer Res 10(1):114

10. Bruix J, Sherman M, Llovet JM et al. Clinical management of hepatocellular carcinoma. Conclusions of the Barcelona-2000 EASL conference. European Association for the Study of the Liver. Journal of hepatology. 2001;35(3):421-430 
11. Hoyt K, Castaneda B, Zhang M et al (2008) Tissue elasticity properties as biomarkers for prostate cancer. Cancer biomarkers: section A of Disease markers 4(4-5):213-225

12. Tuxhorn JA, Ayala GE, Rowley DR (2001) Reactive stroma in prostate cancer progression. The Journal of urology 166(6):2472-2483

13. Provenzano PP, Inman DR, Eliceiri KW et al (2008) Collagen density promotes mammary tumor initiation and progression. BMC medicine 6:11

14. Kaushik S, Pickup MW, Weaver VM (2016) From transformation to metastasis: deconstructing the extracellular matrix in breast cancer. Cancer Metastasis Rev 35(4):655-667

15. Northey JJ, Barrett AS, Acerbi I et al (2020) Stiff stroma increases breast cancer risk by inducing the oncogene ZNF217. J Clin Invest 130(11):5721-5737

16. Glaser KJ, Manduca A, Ehman RL (2012) Review of MR elastography applications and recent developments. Journal of magnetic resonance imaging: JMRI 36(4):757-774

17. Manduca A, Oliphant TE, Dresner MA et al (2001) Magnetic resonance elastography: non-invasive mapping of tissue elasticity. Medical image analysis 5(4):237-254

18. Mariappan YK, Glaser KJ, Ehman RL (2010) Magnetic resonance elastography: a review. Clinical anatomy (New York NY) 23(5):497-511

19. Muthupillai R, Lomas DJ, Rossman PJ, Greenleaf JF, Manduca A, Ehman RL (1995) Magnetic resonance elastography by direct visualization of propagating acoustic strain waves. Science (New York NY) 269(5232):1854-1857

20. Mann RM, Balleyguier C, Baltzer PA et al (2015) Breast MRI: EUSOBI recommendations for women's information. European radiology 25(12):3669-3678

21. Monticciolo DL, Newell MS, Moy L, Niell B, Monsees B, Sickles EA (2018) Breast Cancer Screening in Women at Higher-Than-Average Risk: Recommendations From the ACR. J Am Coll Radiol 15(3 Pt A):408-414

22. Sardanelli F, Boetes C, Borisch B et al (2010) Magnetic resonance imaging of the breast: recommendations from the EUSOMA working group. Eur J Cancer 46(8):1296-1316

23. Saslow D, Boetes C, Burke W et al (2007) American Cancer Society guidelines for breast screening with MRI as an adjunct to mammography. CA Cancer J Clin 57(2):75-89

24. Patel BK, Samreen N, Zhou Y et al. MR Elastography of the Breast: Evolution of Technique, Case Examples, and Future Directions. Clinical breast cancer. 2020

25. O'Flynn EAM, deSouza NM (2011) Functional magnetic resonance: biomarkers of response in breast cancer. Breast Cancer Research 13(1):204

26. ACR BI-RADS atlas: breast imaging reporting and data system. 5th ed. Reston, VA: American College of Radiology; 2013

27. Butcher DT, Alliston T, Weaver VM (2009) A tense situation: forcing tumour progression. Nat Rev Cancer 9(2):108-122 
28. Conklin MW, Eickhoff JC, Riching KM et al (2011) Aligned collagen is a prognostic signature for survival in human breast carcinoma. Am J Pathol 178(3):1221-1232

29. Bartow SA, Pathak DR, Mettler FA, Key CR, Pike MC (1995) Breast mammographic pattern: a concatenation of confounding and breast cancer risk factors. Am J Epidemiol 142(8):813-819

30. Boyd NF, Jensen HM, Cooke G, Han HL (1992) Relationship between mammographic and histological risk factors for breast cancer. J Natl Cancer Inst 84(15):1170-1179

31. Gabrielson M, Chiesa F, Paulsson J et al (2016) Amount of stroma is associated with mammographic density and stromal expression of oestrogen receptor in normal breast tissues. Breast Cancer Res Treat 158(2):253-261

32. Ghosh K, Brandt KR, Reynolds C et al (2012) Tissue composition of mammographically dense and non-dense breast tissue. Breast Cancer Res Treat 131(1):267-275

33. Hawes D, Downey S, Pearce CL et al (2006) Dense breast stromal tissue shows greatly increased concentration of breast epithelium but no increase in its proliferative activity. Breast Cancer Res $8(2): R 24$

34. Huo CW, Chew G, Hill P et al (2015) High mammographic density is associated with an increase in stromal collagen and immune cells within the mammary epithelium. Breast Cancer Res 17(1):79

35. Li T, Sun L, Miller $\mathrm{N}$ et al (2005) The association of measured breast tissue characteristics with mammographic density and other risk factors for breast cancer. Cancer Epidemiol Biomarkers Prev 14(2):343-349

36. Turashvili G, McKinney S, Martin L et al (2009) Columnar cell lesions, mammographic density and breast cancer risk. Breast Cancer Res Treat 115(3):561-571

37. Kai F, Drain AP, Weaver VM (2019) The Extracellular Matrix Modulates the Metastatic Journey. Dev Cell 49(3):332-346

38. Northcott JM, Dean IS, Mouw JK, Weaver VM (2018) Feeling Stress: The Mechanics of Cancer Progression and Aggression. Front Cell Dev Biol 6:17

39. Conklin MW, Keely PJ (2012) Why the stroma matters in breast cancer: insights into breast cancer patient outcomes through the examination of stromal biomarkers. Cell adhesion migration 6(3):249260

40. Lopez JI, Kang I, You WK, McDonald DM, Weaver VM (2011) In situ force mapping of mammary gland transformation. Integrative biology: quantitative biosciences from nano to macro 3(9):910921

41. Maller O, Hansen KC, Lyons TR et al (2013) Collagen architecture in pregnancy-induced protection from breast cancer. Journal of cell science 126(Pt 18):4108-4110

42. Giussani M, Merlino G, Cappelletti V, Tagliabue E, Daidone MG (2015) Tumor-extracellular matrix interactions: Identification of tools associated with breast cancer progression. Seminars in cancer biology $35: 3-10$ 
43. Liu PF, Debatin JF, Caduff RF, Kacl G, Garzoli E, Krestin GP (1998) Improved diagnostic accuracy in dynamic contrast enhanced MRI of the breast by combined quantitative and qualitative analysis. The British journal of radiology 71(845):501-509

44. Lorenzen J, Sinkus R, Lorenzen M et al (2002) MR elastography of the breast:preliminary clinical results. RoFo: Fortschritte auf dem Gebiete der Rontgenstrahlen der Nuklearmedizin 174(7):830-834

45. Sinkus R, Siegmann K, Xydeas T, Tanter M, Claussen C, Fink M (2007) MR elastography of breast lesions: understanding the solid/liquid duality can improve the specificity of contrast-enhanced MR mammography. Magnetic resonance in medicine 58(6):1135-1144

46. Xydeas T, Siegmann K, Sinkus R, Krainick-Strobel U, Miller S, Claussen CD (2005) Magnetic resonance elastography of the breast: correlation of signal intensity data with viscoelastic properties. Investigative radiology 40(7):412-420

47. Sprague BL, Gangnon RE, Burt V et al. Prevalence of mammographically dense breasts in the United States. J Natl Cancer Inst. 2014;106(10)

48. Berg WA (2016) Current Status of Supplemental Screening in Dense Breasts. J Clin Oncol 34(16):1840-1843

49. Throckmorton AD, Rhodes DJ, Hughes KS, Degnim AC, Dickson-Witmer D (2016) Dense Breasts: What Do Our Patients Need to Be Told and Why? Ann Surg Oncol 23(10):3119-3127

50. Vourtsis A, Berg WA (2019) Breast density implications and supplemental screening. European radiology 29(4):1762-1777

51. Lee CH, Dershaw DD, Kopans D et al (2010) Breast cancer screening with imaging: recommendations from the Society of Breast Imaging and the ACR on the use of mammography, breast MRI, breast ultrasound, and other technologies for the detection of clinically occult breast cancer. J Am Coll Radiol 7(1):18-27

52. Tagliafico AS, Calabrese M, Mariscotti G et al (2016) Adjunct Screening With Tomosynthesis or Ultrasound in Women With Mammography-Negative Dense Breasts: Interim Report of a Prospective Comparative Trial. J Clin Oncol 34(16):1882-1888

53. Chin L, Andersen JN, Futreal PA (2011) Cancer genomics: from discovery science to personalized medicine. Nat Med 17(3):297-303

54. Hamburg MA, Collins FS (2010) The path to personalized medicine. N Engl J Med 363(4):301-304

55. Keen JD (2011) Analysis of health benefits and cost-effectiveness of mammography for breast cancer. Ann Intern Med 155(8):566; author reply 566-567

56. Jud SM, Häberle L, Fasching PA et al (2012) Correlates of mammographic density in B-mode ultrasound and real time elastography. Eur J Cancer Prev 21(4):343-349

57. Li X, Wang JN, Fan ZY et al (2015) Determination of the Elasticity of Breast Tissue during the Menstrual Cycle Using Real-Time Shear Wave Elastography. Ultrasound Med Biol 41(12):3140-3147

58. Pepin KM, Ehman RL, McGee KP (2015) Magnetic resonance elastography (MRE) in cancer: Technique, analysis, and applications. Prog Nucl Magn Reson Spectrosc 90-91:32-48 
59. Chen JH, Chan S, Zhang Y, Li S, Chang RF, Su MY (2019) Evaluation of breast stiffness measured by ultrasound and breast density measured by MRI using a prone-supine deformation model. Biomark Res 7:20

60. Golatta M, Schweitzer-Martin M, Harcos A et al (2013) Normal breast tissue stiffness measured by a new ultrasound technique: virtual touch tissue imaging quantification (VTIQ). European journal of radiology 82(11):e676-e679

61. Hawley JR, Kalra P, Mo X, Raterman B, Yee LD, Kolipaka A (2017) Quantification of breast stiffness using MR elastography at 3 Tesla with a soft sternal driver: A reproducibility study. J Magn Reson Imaging 45(5):1379-1384

62. Armstrong K, Eisen A, Weber B (2000) Assessing the risk of breast cancer. N Engl J Med 342(8):564571

63. Brentnall AR, Cohn WF, Knaus WA, Yaffe MJ, Cuzick J, Harvey JA (2019) A Case-Control Study to Add Volumetric or Clinical Mammographic Density into the Tyrer-Cuzick Breast Cancer Risk Model. J Breast Imaging 1(2):99-106

64. Tice JA, Cummings SR, Ziv E, Kerlikowske K (2005) Mammographic breast density and the Gail model for breast cancer risk prediction in a screening population. Breast Cancer Res Treat 94(2):115-122

65. del Carmen MG, Halpern EF, Kopans DB et al (2007) Mammographic breast density and race. AJR Am J Roentgenol 188(4):1147-1150

66. McCarthy AM, Keller BM, Pantalone LM et al. Racial Differences in Quantitative Measures of Area and Volumetric Breast Density. J Natl Cancer Inst. 2016;108(10)

67. Razzaghi H, Troester MA, Gierach GL, Olshan AF, Yankaskas BC, Millikan RC (2012) Mammographic density and breast cancer risk in White and African American Women. Breast Cancer Res Treat 135(2):571-580

68. Gard CC, Aiello Bowles EJ, Miglioretti DL, Taplin SH, Rutter CM (2015) Misclassification of Breast Imaging Reporting and Data System (BI-RADS) Mammographic Density and Implications for Breast Density Reporting Legislation. Breast J 21(5):481-489

69. Redondo A, Comas M, Macià F et al (2012) Inter- and intraradiologist variability in the BI-RADS assessment and breast density categories for screening mammograms. Br J Radiol 85(1019):14651470

70. Balleyguier C, Lakhdar AB, Dunant A, Mathieu MC, Delaloge S, Sinkus R. Value of whole breast magnetic resonance elastography added to MRI for lesion characterization. NMR in biomedicine. 2018;31(1)

71. McKnight AL, Kugel JL, Rossman PJ, Manduca A, Hartmann LC, Ehman RL (2002) MR elastography of breast cancer: preliminary results. AJR American journal of roentgenology 178(6):1411-1417

72. Sinkus R, Lorenzen J, Schrader D, Lorenzen M, Dargatz M, Holz D (2000) High-resolution tensor MR elastography for breast tumour detection. Physics in medicine biology 45(6):1649-1664 


\section{Figures}

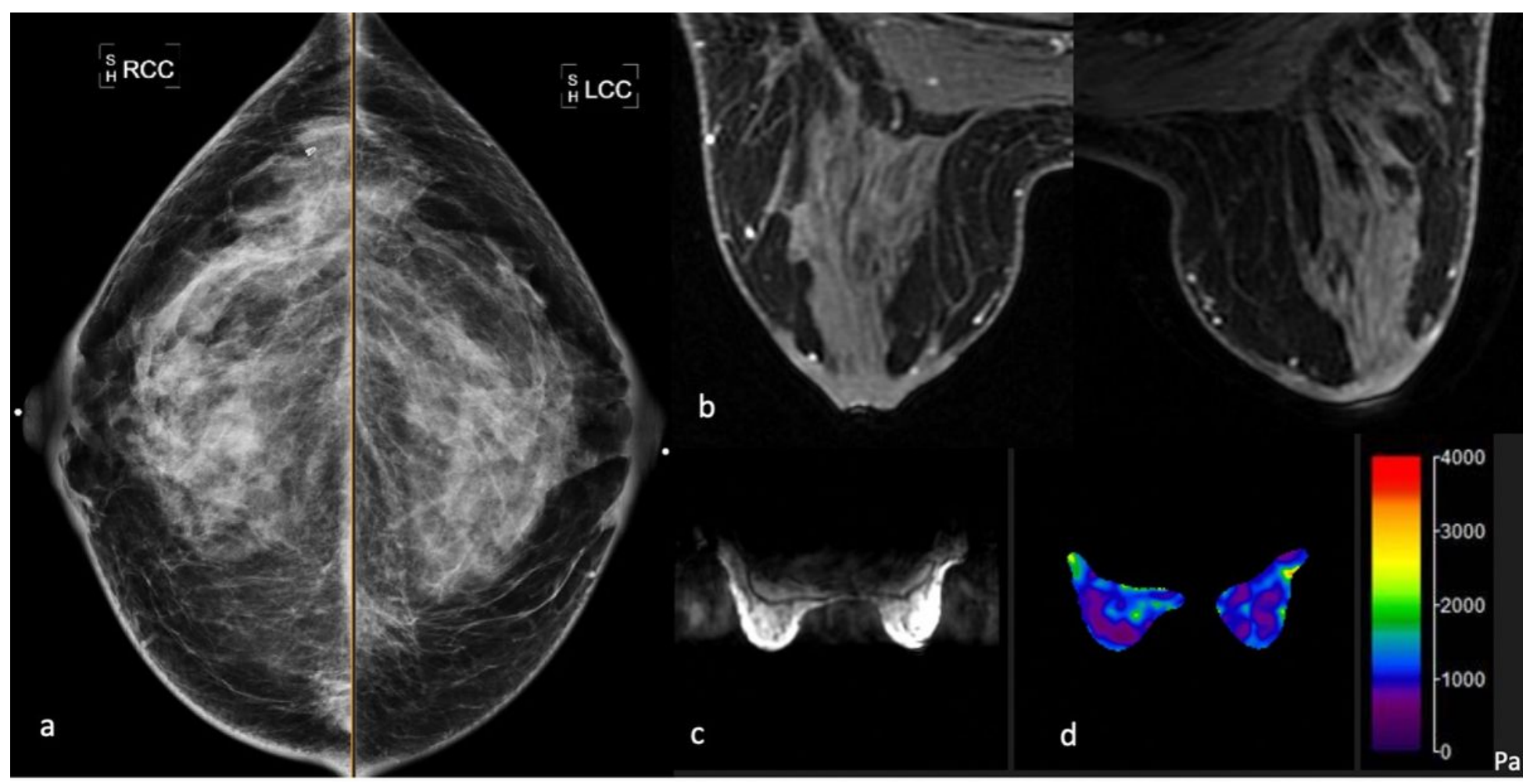

\section{Figure 1}

50 year old average risk female with a) dense breasts on negative screening mammography, b) Postcontrast breast MRI was negative for imaging abnormalities, mild bilateral benign background parenchymal enhancement, c) MR magnitude map demonstrates anatomical anatomy to delineate central slice d) corresponding elastogram map shows mild symmetric bilateral stiffness ranging within $0.5-1.0 \mathrm{kPa}$. 


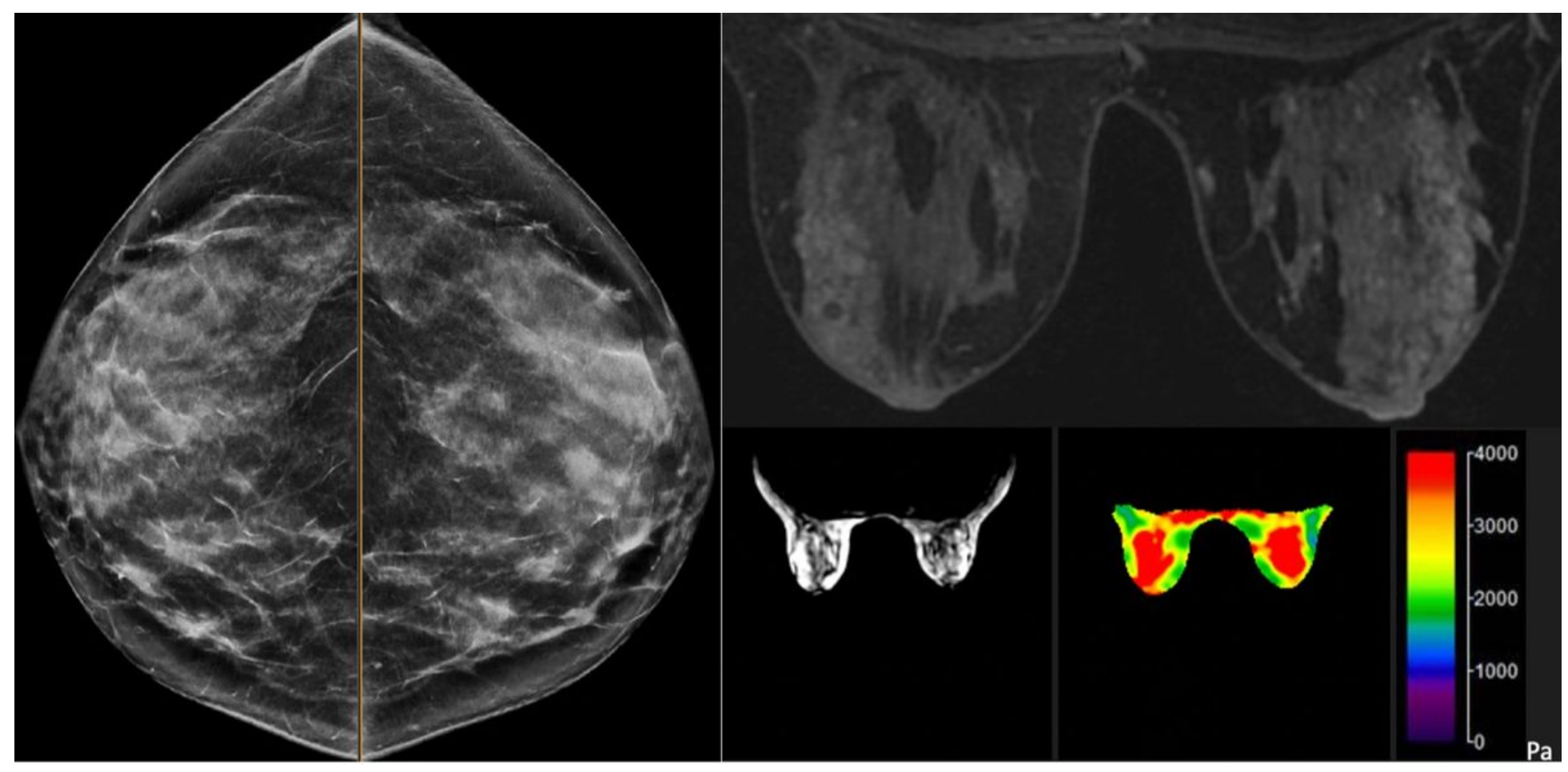

Figure 2

41 year old female with significant history of maternal aunt with BRCA 2 mutation carrier, maternal history of breast cancer, IBIS model $29 \%$ a) dense breasts on negative screening mammography, b) postcontrast breast MRI was negative for imaging abnormalities, mild bilateral benign background parenchymal enhancement, c) MR magnitude map demonstrates anatomical anatomy to delineate central slice d) corresponding elastogram map shows mild symmetric bilateral stiffness ranging within 2.0-4.0 kPa. 


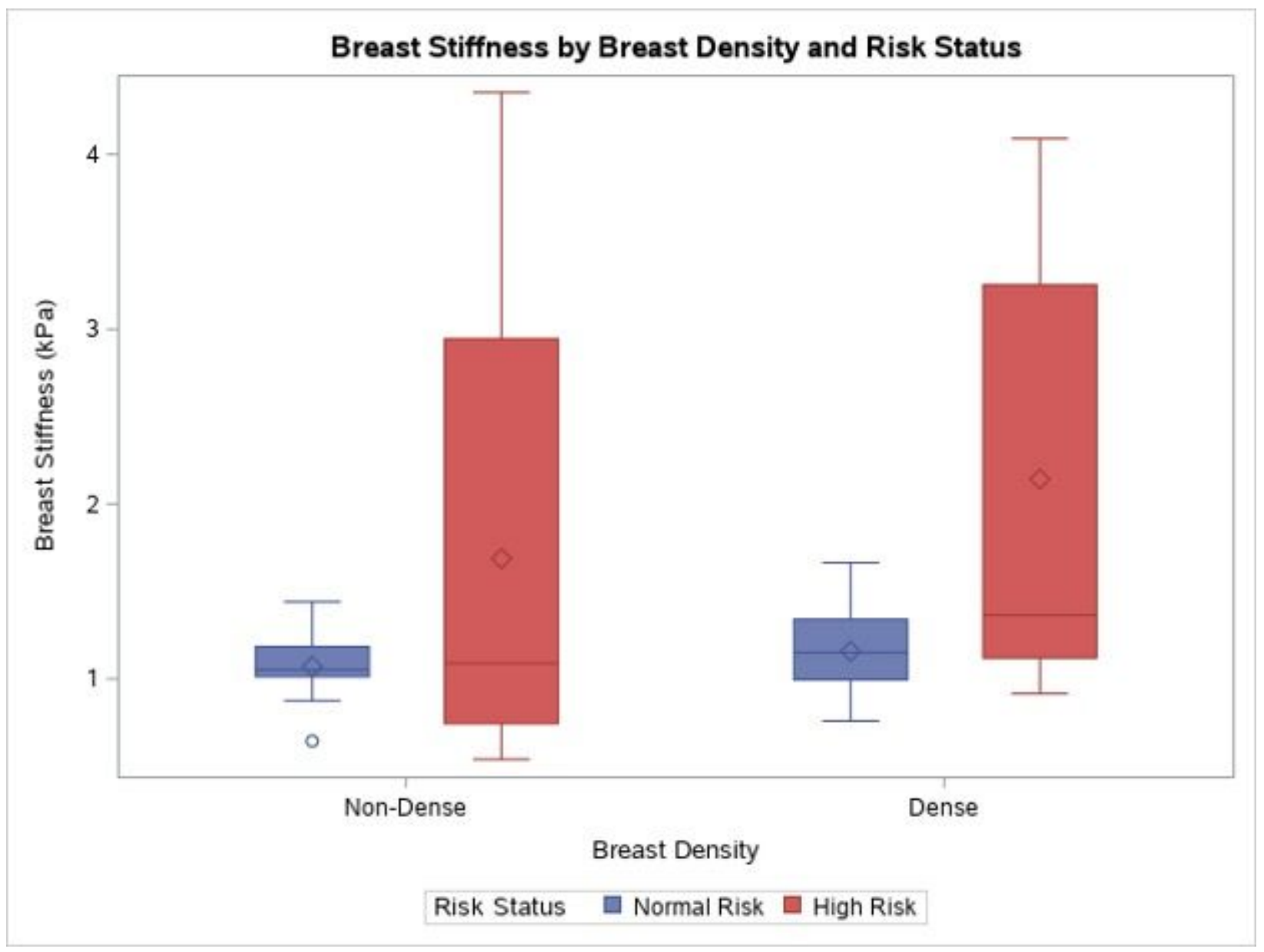

\section{Figure 3}

Box and whisker plot of breast stiffness (averaged across the left and right breasts) by breast density and risk status. High risk patients with dense breasts had greater breast stiffness compared to normal risk patients with dense breasts. The box represents the interquartile range, the horizontal line within each box represents the median, and the diamond within each box represents the mean. 


\section{Breast Stiffness by Biopsy/Surgery for High Risk Women with Dense Breasts}

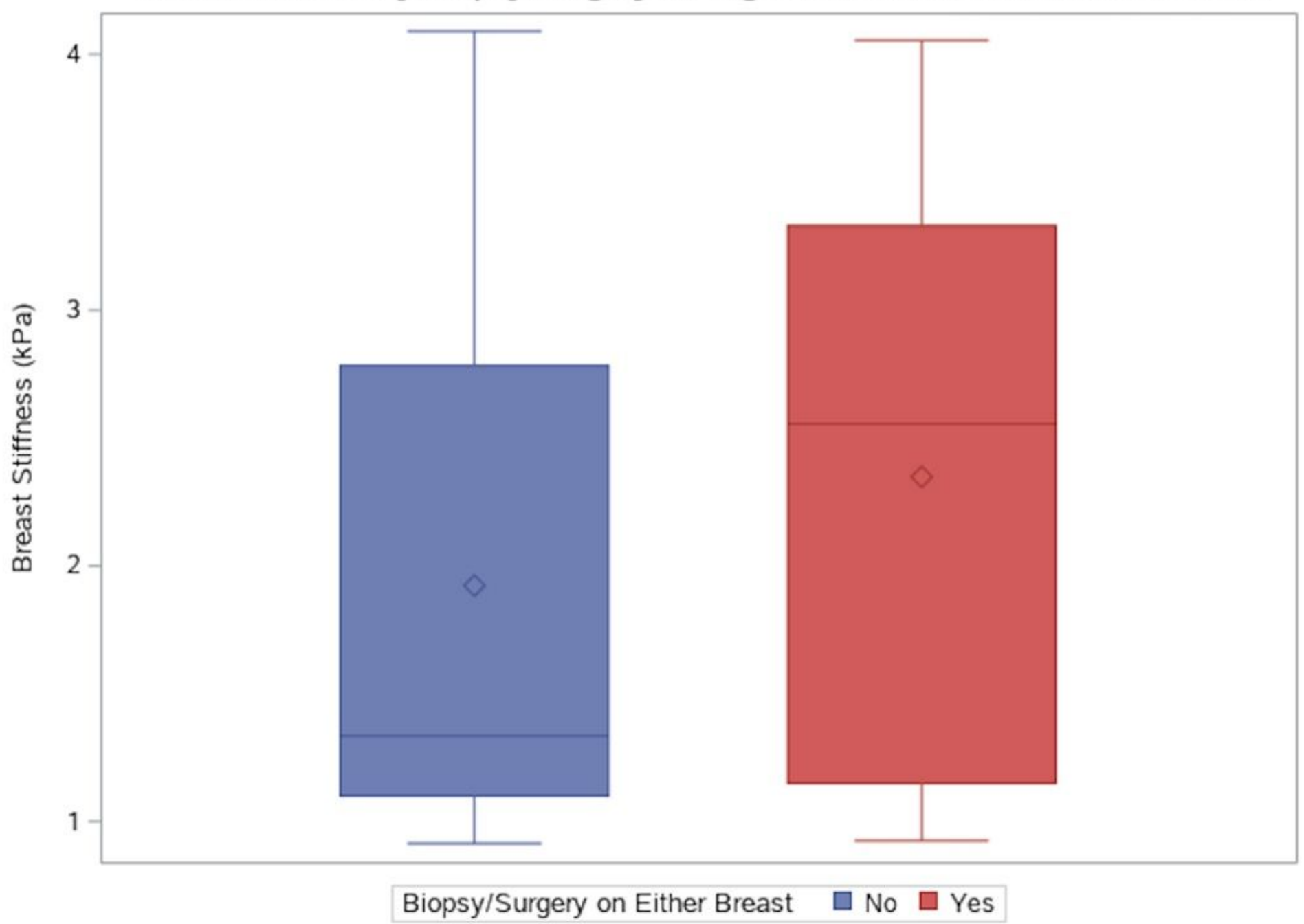

Figure 4

Box and whisker plot of breast stiffness (averaged across the left and right breasts) by biopsy/surgery in high risk patients. 24 high risk women with dense breasts and no biopsy/surgery and 30 high risk women with dense breasts and biopsy/surgery in either or both breasts. The horizontal line within each box represents the median, and the diamond within each box represents the mean. The breast stiffness median $=1.34$ versus 2.56 in the no biopsy/surgery versus biopsy surgery group. The breast stiffness mean $=1.92$ versus 2.35 in the no biopsy/surgery versus biopsy surgery group. These means were not significantly different. 


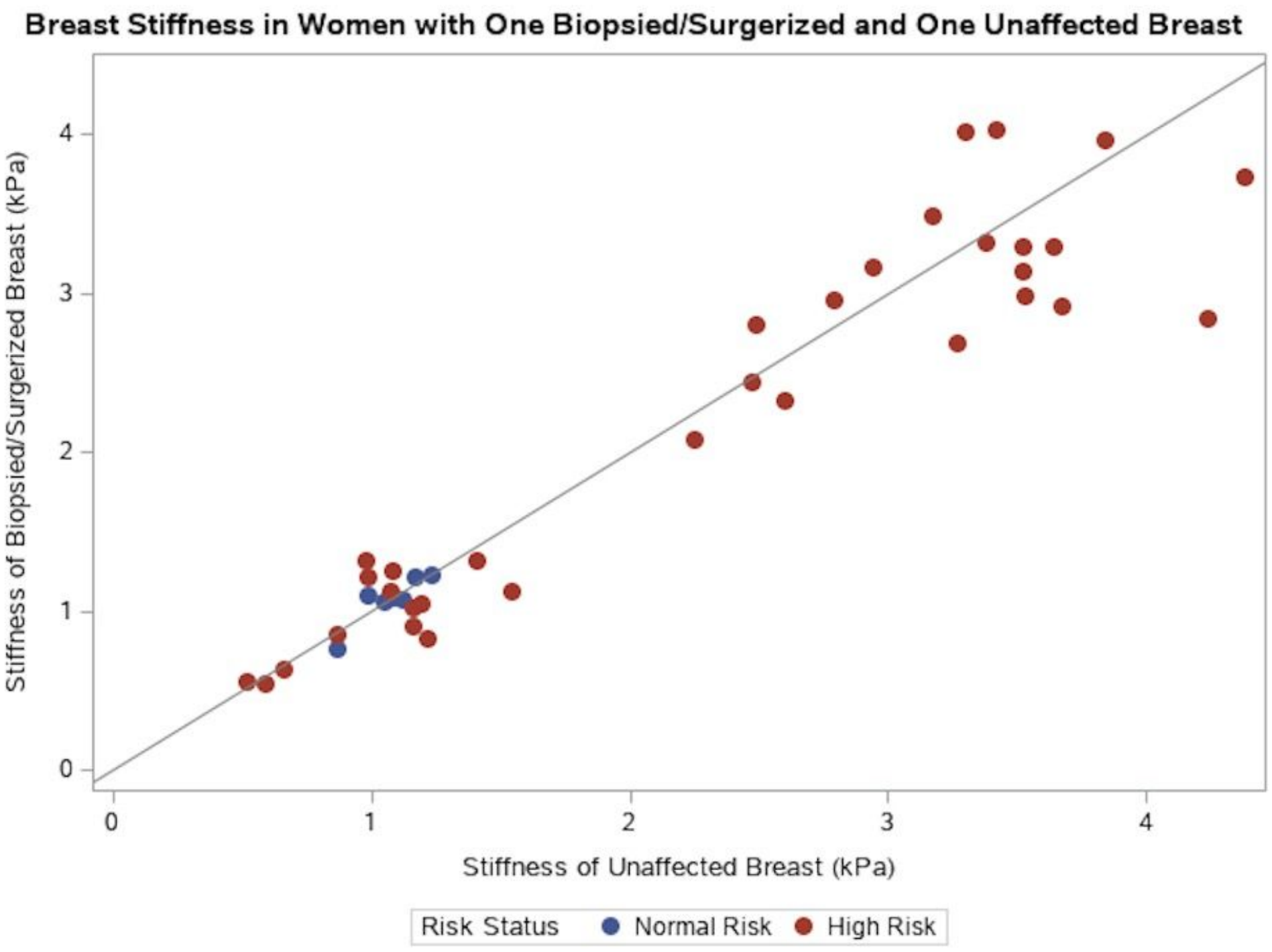

Figure 5

Stiffness of surgerized/unaffected breast scatterplot. The blue markers represent normal risk women, and the red markers represent high risk women. The diagonal line represents perfect agreement for stiffness between a woman's biopsied/surgerized breast and unaffected breast. 